\title{
Sociodemographic characteristics associated with blindness in a Nile Delta governorate of Egypt
}

\author{
D Fouad, A Mousa, P Courtright
}

Br J Ophthalmol 2004;88:614-618. doi: 10.1136/bjo.2003.026997

Series editors: W V Good and S Ruit

See end of article for authors' affiliations ....................

Correspondence to: Dr P Courtright Kilimanjaro Centre for Community

Ophthalmology, Tumaini

University, PO Box 2254,

Moshi, Tanzania;

pcourtright@kcmc.ac.tz

Accepted 1 October 2003
Background: Globally, blindness is associated with old age and being female. Other sociodemographic and socioeconomic status characteristics associated with blindness have included educational attainment, and occupation. These factors reflect exposure to specific risk factors for blinding eye diseases and utilisation of preventive and curative services by specific sectors of the population.

Methods: A population based survey of blindness and trachoma was conducted in Menofiya governorate in Egypt. 3322 adults 50 years of age and over were sampled from throughout the governorate (population 2.7 million). Visual acuity and clinical conditions were recorded and interviews with respondents were conducted.

Results: Overall, blindness ( $<6 / 60$ presenting vision in the better eye) was recorded in $13 \%$ of the study population. Besides age and sex, other factors associated with blindness (logistic regression) were marital status and poor sanitation in the household.

Conclusion: Socioeconomic status does not appear to be a significant factor associated with blindness in adults in this setting. Instead, sociocultural factors, in particular, characteristics associated with gender sensitive decision making within households, are likely to be more important considerations in understanding blindness in these communities. Successfully combating blindness in the Nile Delta of Egypt will require gender sensitive efforts aimed at timely and effective utilisation of eye care services.
$\mathrm{T}$ he global magnitude of blindness (better eye presenting vision of $<3 / 60)$ is estimated at 50 million and is expected to increase to 75 million by the year 2020 unless significant efforts are made to prevent this. ${ }^{12}$ A further 150 million people are estimated to be visually impaired (better eye presenting vision of 6/24-3/60). The magnitude of vision loss has been steadily increasing worldwide for a number of reasons; increasing life expectancy and population growth in the developing world are the most important contributors to this trend. Almost $80 \%$ of global blindness is avoidable and $90 \%$ of blind people live in developing countries. ${ }^{1}$ In many developing countries (Egypt included) blindness is defined as $<6 / 60$ (better eye presenting vision), rather than $<3 / 60$ (better eye presenting vision). Accordingly, global estimates of blindness at the more liberal cut off are expected to be considerably higher (up to 75-85 million).

Vision 2020, a global initiative by the World Health Organization, non-governmental organisations, and others aims to eliminate avoidable blindness by the year 2020 through specific strategies aimed at the primary causes of blindness. National strategic Vision 2020 plans have been developed in a number of countries and Egypt is likely to have its plan in place in 2004. Development of a national plan requires understanding of blindness, utilisation of services, and ophthalmological capacity in a population.

Increasing age is the most important predictor of blindness; however, female sex (independent of age) is also associated with blindness. ${ }^{3}$ Low educational attainment and low socioeconomic status have also been shown to be associated with blindness. ${ }^{45}$ Low utilisation of service by those with low educational attainment and low socioeconomic status is thought to be responsible for the higher blindness rates in these groups.

There have been very few surveys of blindness in Egypt. The largest survey, consisting of 11000 rural and urban residents of the Nile Delta, was carried out starting in 1965 near Alexandria. ${ }^{6-8}$ Blindness (defined as better eye, presenting vision $<6 / 60$ ) was detected in $2.1 \%$ of men and $3.2 \%$ of women (all age groups), This varied from $0.9 \%$ and $1.2 \%$ of urban men and women respectively to $2.9 \%$ and $5.3 \%$ of rural men and women respectively. Among the age group 50 and over blindness was recorded in $11.1 \%$ of men and $21.0 \%$ of women. For both sexes, the rural prevalence were about three times higher than the urban prevalence. A 1985 survey of blindness and trachoma in a rural Nile Delta hamlet found $17 \%$ of those age 50 and over to be blind $(<3 / 60)$ with women having about twice the prevalence of blindness $(22 \%)$ as men (11\%). ${ }^{9}$ No analysis of sociodemographic characteristics was carried out in either of these two studies.

We conducted a survey of blindness in Menofiya Governorate, Egypt, in order to determine the prevalence of blindness and low vision in the adult population (50+ years of age), to identify the three leading causes of blindness, and to determine the prevalence of trachoma. We have previously reported findings on trachoma. ${ }^{10}$ We also sought to assess blindness according to previously suggested demographic and socioeconomic characteristics.

\section{METHODS}

Menofiya is a Nile Delta governorate $82 \mathrm{~km}$ northwest of Cairo. The estimated (1997) population was 2760431 , among whom 334024 (12.1\%) were age 50 and over, similar to 1965. Population density in Menofiya is high with 1800 people per square $\mathrm{km}$. While most of the population is rural, there are a number of urban centres in the governorate. There are 269 government health units, giving a population per health unit of 10261 . There are three eye hospitals and a university hospital with an eye department. In addition, there are many private eye clinics. There are 30 ophthalmologists giving an ophthalmologist to population ratio of $1: 92000$ inhabitants.

The survey methods have been previously described. ${ }^{10}$ Briefly, the sample size was calculated according to the age composition of the population to be sampled and the 
expected prevalence of blindness (around 2\% of those 50 years and above). The total sample size was calculated to be 3000 adults (age 50+). The villages and their respective populations were listed with cumulative populations to reach the total population of the governorate. From this list 60 numbers were randomly selected which became the sampling clusters; in some cases more than one cluster was identified per village. No stratification (rural/urban) was undertaken. For each cluster a rough map was drawn; this was divided into sectors (number of sectors depending upon the layout of the village) and one was randomly selected. Starting from a random point selected in the sector the index household was chosen. Every fifth nearest door was selected as the next household. Within each household all residents were enumerated and when 50 adults (age 50+) were listed, enumeration stopped. There were no exclusion criteria.

The enumerators completed a form on characteristics of the village and of the individual household. Examination was carried out at the household. The eye examination form was completed by the visual acuity tester (for visual acuity) and by the examining ophthalmologist (for clinical assessment of vision loss). Visual acuity was measured by a trained eye nurse using an E optotype at a standard 6 metres. The chart was always set up with sun at the back of the person being tested. Presenting visual acuity was measured by eye and pinhole vision was tested among those with vision $<6 / 18$; for assessment of vision in the individual we used best eye vision. In Egypt blindness is defined as $<6 / 60$, which is the cut off we have used throughout this paper. Loupes $(2.5 \times)$ and torches were used for external examination and a direct ophthalmoscope was used by the examining ophthalmologist to examine the lens and posterior pole of those who had a vision of $<6 / 18$ after pinhole correction. All cases requiring surgical intervention were referred for free surgery at the nearest Ministry of Health eye hospital. All examiners had a standard pre-survey training to standardise examination technique and determination of cause of blindness. There were two follow up visits to households in which there were missing adults to try to increase the survey coverage. In a few cases the individual to be examined was bedridden and testing of visual acuity was not feasible. These cases were identified as "believed not blind" or "believed blind." The study was approved by the Ministry of Health and consent was requested at the village and household level.

Data, collected daily by the field team, were entered on computer (Microsoft Access) by the Al Noor Foundation team in Cairo, and checked for inconsistencies. Data analysis was carried out using SPSS 11, Minitab 13, and Epi-Info 2000 software according to a previously designed plan of analysis. Odds ratios and $95 \%$ confidence intervals were calculated for presentation of univariate data analysis. Confidence intervals were calculated assuming that blindness did not cluster at the household and community level. Logistic regression (forward stepwise) analysis was used to calculate adjusted odds ratios and $95 \%$ confidence intervals.

\section{RESULTS}

The 60 clusters ( 17 urban and 43 rural) comprised 47 villages. From the sampled clusters 3322 adults were enumerated and, among them, $2426(80.8 \%)$ were examined. Men in the age group 50-59 years were the least likely to be examined, primarily because of their frequent work outside of their village.

Overall, $1289(53.1 \%)$ of those examined had good vision (presenting vision of $6 / 18$ or better in the better eye) while $308(12.7 \%)$ of the sampled population had a vision of $<6 / 60$ and five $(0.2 \%)$ were believed blind, giving an overall blindness prevalence of $12.9 \% \quad(95 \%$ CI 11.6 to 14.2 ) (table 1) The main causes of blindness were found to be cataract or uncorrected aphakia $(64.0 \%$ overall; $58.5 \%$ among men and $67.4 \%$ among women), corneal opacities (trachoma and other causes) $(30.2 \%$ overall; $27.9 \%$ among men and $31.6 \%$ among women), and others (glaucoma, refractive errors, retinal conditions) $(5.8 \%$ overall; $13.6 \%$ among men and $1.1 \%$ among women). The cataract surgical coverage was $13 \%$, similar for men and women. Among the eyes with evidence of cataract surgery only $9.4 \%$ had an IOL; among the patients with aphakic surgery $44 \%$ had a presenting vision of $<6 / 60$.

As expected, blindness increased with age. Univariate analysis showed that sociodemographic factors associated with blindness included age, sex (being female), marital status (being currently unmarried), number of children in the household (few children living in the house), rural residence, occupation (farming and not contributing to household income), education (illiterate), primary source of income (renting land for farming and others), and sanitation (not on general sanitation network) (table 2). Almost half of all of the blind were 70 years of age and over.

Many of the socioeconomic and demographic parameters were interrelated. For example, educational attainment was associated with occupation and source of income. Unmarried women (primarily widows) comprised $40.6 \%$ of women surveyed while unmarried men accounted for only $14.2 \%$ of men surveyed. There was no difference in marital status (by sex) among those examined and those not examined (data not shown). Being unmarried increased the odds of blindness 3.2-fold compared to being married. Forward stepwise logistic regression analysis (including all variables associated, $\mathrm{p}<0.05$, with blindness by univariate analysis and a threshold criterion of acceptance of $\mathrm{p}<0.05)$ revealed that age, sex (being female), marital status (being unmarried), and sanitation (not being on the general network) remained independently associated with blindness (table 3 ). Only one person $(2.9 \%)$ blind because of trachoma was on the general sanitation network compared to 36 people $(13.0 \%)$ of those not on a general sanitation network. $(\mathrm{OR}=4.3,95 \%$ CI 0.57 to 32.8 ).

\section{DISCUSSION}

Extrapolation of our findings to the entire governorate would suggest that there are an estimated 29766 people blind and

\begin{tabular}{|c|c|c|c|}
\hline & Men & Women & Both \\
\hline Visual acuity & No (\%) & No (\%) & No (\%) \\
\hline Normal (6/18+) & $638(59.0)$ & $651(48.4)$ & $1289(53.1)$ \\
\hline Visual impaired $(6 / 24-6 / 60)$ & $315(29.1)$ & $495(36.8)$ & $810(33.4)$ \\
\hline Severe visual impairment $(5 / 60-3 / 60)$ & $35(3.2)$ & $81(6.0)$ & $116(4.8)$ \\
\hline Blind $(<3 / 60)$ & $83(7.7)$ & $109(8.1)$ & $192(7.9)$ \\
\hline Believed not blind & $10(0.9)$ & $4(0.3)$ & $14(0.6)$ \\
\hline Believed blind & $1(0.1)$ & $4(0.3)$ & $5(0.2)$ \\
\hline Total & 1082 & 1344 & 2426 \\
\hline
\end{tabular}


Table 2 Blindness $(<6 / 60)$ by sociodemographic factors in the adult population

\begin{tabular}{|c|c|c|c|}
\hline & \multirow{2}{*}{$\frac{\text { Blind }}{\text { No (\%) }}$} & \multirow{2}{*}{$\frac{\text { Not blind }}{\text { No (\%) }}$} & \multirow{2}{*}{$\frac{\text { Odds ratio }}{95 \% \mathrm{Cl}}$} \\
\hline & & & \\
\hline \multicolumn{4}{|l|}{ Age group } \\
\hline $50-59$ & $53(17.2)$ & $1136(53.6)$ & 1.0 \\
\hline $60-69$ & $110(35.7)$ & $693(32.7)$ & $3.40(2.39$ to 4.86$)$ \\
\hline $70+$ years & $145(47.1)$ & $289(13.6)$ & 10.75 (7.55 to 15.43$)$ \\
\hline \multicolumn{4}{|r|}{ ו } \\
\hline Male & $118(38.3)$ & $964(45.5)$ & 1.0 \\
\hline Female & $190(61.7)$ & $1154(54.5)$ & 1.35 (1.05 to 1.73 ) \\
\hline \multicolumn{4}{|l|}{ Marital status } \\
\hline Married & $137(47.9)$ & 1505 (74.7) & 1.0 \\
\hline Unmarried & $149(52.1)$ & $511(25.3)$ & $3.20(2.47$ to 4.16$)$ \\
\hline Missing & 22 & 102 & \\
\hline \multicolumn{4}{|c|}{ Number of children in household } \\
\hline $0-4$ children & $246(95.0)$ & $1659(85.6)$ & $3.18(1.75$ to 5.90$)$ \\
\hline $5+$ children & $13(5.0)$ & 279 (14.4) & 1.0 \\
\hline Missing & 49 & 180 & \\
\hline \multicolumn{4}{|c|}{ Number of people living in household } \\
\hline 1-7 people & $175(57.6)$ & $1225(58.4)$ & 1.0 \\
\hline 8+ people & $129(42.4)$ & $874(41.6)$ & $1.03(0.81$ to 1.32$)$ \\
\hline Missing & 4 & 19 & \\
\hline \multicolumn{4}{|l|}{ Residence } \\
\hline Urban & $65(21.1)$ & $580(27.4)$ & 1.0 \\
\hline Rural & $243(78.9)$ & $1538(72.6)$ & $1.36(1.01$ to 1.84$)$ \\
\hline Occupation & & & \\
\hline Worker/official & $23(7.3)$ & $399(18.9)$ & 1.0 \\
\hline Farmer & $61(19.8)$ & $439(20.8)$ & 2.41 (1.43 to 4.09 ) \\
\hline None (retired) & $224(72.7)$ & $1272(60.3)$ & 3.05 (1.93 to 4.89 ) \\
\hline Missing & 0 & 8 & \\
\hline Education & & & \\
\hline Illiterate & $287(93.8)$ & $1816(86.7)$ & 2.31 (1.40 to 3.86 ) \\
\hline Intermediate/high & $19(6.2)$ & $278(13.3)$ & 1.0 \\
\hline Missing & $2-1$ & 24 & \\
\hline Type of building & & & \\
\hline Mud & $149(48.9)$ & $908(43.4)$ & $1.26(0.95$ to 1.67$)$ \\
\hline Stone & $100(32.8)$ & $768(36.7)$ & \\
\hline Other (ind stone) & $56(18.4)$ & 415 (19.8) & $0.82(0.57$ to 1.16$)$ \\
\hline Missing & 3 & 27 & \\
\hline Sanitation & & & \\
\hline General network & $30(9.8)$ & $301(14.4)$ & 1.0 \\
\hline Latrine in house & $229(74.6)$ & 1538 (73.7) & $1.49(0.99$ to 2.28$)$ \\
\hline Latrine outside house & $27(8.8)$ & $168(8.1)$ & $1.61(0.93$ to 2.90$)$ \\
\hline Others & $21(6.8)$ & $79(3.8)$ & 2.67 (1.39 to 5.12$)$ \\
\hline Missing & 1 & 32 & \\
\hline Primary source of income & & & \\
\hline Own farming & 40 (13.4) & $344(16.7)$ & 0.75 (0.40 to 1.40$)$ \\
\hline Rent farming & 64 (21.4) & 377 (18.4) & 1.09 (0.61 to 1.97$)$ \\
\hline Employment & $73(24.4)$ & $650(31.6)$ & $0.72(0.41$ to 1.29$)$ \\
\hline Trading & $19(6.4)$ & $122(5.9)$ & 1.0 \\
\hline Other & $103(34.4)$ & $561(27.3)$ & $1.18(0.68$ to 2.70$)$ \\
\hline Missing & 9 & 64 & \\
\hline Water source & & & \\
\hline Piped village tap & $24(7.9)$ & $179(8.6)$ & $0.91(0.57$ to 1.46$)$ \\
\hline Piped household tap & $243(79.7)$ & $1658(80.0)$ & \\
\hline Village/household well & $20(6.6)$ & $141(6.8)$ & $0.97(0.58-1.61)$ \\
\hline Canal & $18(5.9)$ & $95(4.6)$ & $1.29(0.74$ to 2.23 ) \\
\hline Missing & 3 & 45 & \\
\hline Type of electricity & & & \\
\hline General network & $304(99.3)$ & 2062 (99.4) & 1.0 \\
\hline Other source & $2(0.7)$ & $13(0.6)$ & $1.04(0.28$ to 3.78$)$ \\
\hline Missing & 2 & 43 & \\
\hline Access to radio & & & \\
\hline Yes & $288(93.5)$ & 1975 (93.2) & 1.0 \\
\hline No & $20(6.5)$ & $143(6.8)$ & 0.96 (0.57 to 1.59$)$ \\
\hline Access to TV & & & \\
\hline Yes & $288(93.5)$ & 2000 (94.4) & \\
\hline No & $20(6.5)$ & $118(5.6)$ & $1.18(0.70$ to 1.96$)$ \\
\hline Nearest healthcare facilit & & & \\
\hline$<1 \mathrm{~km}$ & $180(58.4)$ & $830(48.0)$ & 1.0 \\
\hline $1-3 \mathrm{~km}$ & $109(35.4)$ & 765 (44.2) & $0.66(0.50$ to 0.86$)$ \\
\hline$>3 \mathrm{~km}$ & $19(6.2)$ & $135(7.8)$ & 0.65 (0.38 to 1.10$)$ \\
\hline Missing & 0 & 388 & \\
\hline Nearest eye care facility & & & \\
\hline$<3 \mathrm{~km}$ & $99(32.1)$ & $732(34.6)$ & 1.0 \\
\hline $3-5 \mathrm{~km}$ & 66 (21.4) & 387 (18.3) & 1.26 (0.89 to 1.79$)$ \\
\hline 6-8 km & $69(22.4)$ & $478(22.6)$ & $1.07(0.76$ to 1.50$)$ \\
\hline $9+\mathrm{km}$ & $74(24.0)$ & $521(24.6)$ & 1.05 (0.75 to 1.47$)$ \\
\hline
\end{tabular}


Table 3 Sociodemographic characteristics associated with blindness (stepwise logistic regression model)

\begin{tabular}{llll}
\hline Variable & B (SE) & Odds ratio $(95 \%$ CI) & p Value \\
\hline Constant & $-8.636(0.592)$ & 1.78 & 0.000 \\
Age (continuous) & $0.107(0.009)$ & $1.11(1.09$ to 1.13$)$ & 0.000 \\
Sex (= female) & $0.448(0.164)$ & $1.57(1.14$ to 2.16$)$ & 0.006 \\
Marital status (= unmarried) & $0.405(0.165)$ & $1.50(1.09$ to 2.07$)$ & 0.014 \\
Sanitation (index = general network) & & & \\
$\quad$ Latrine in house & $0.545(0.233)$ & $1.73(1.09$ to 2.72$)$ & 0.019 \\
$\quad$ Latrine outside house & $0.665(0.337)$ & $1.94(1.00$ to 3.76$)$ & 0.049 \\
$\quad$ Other & $0.905(0.364)$ & $2.47(1.21$ to 5.04) & 0.013 \\
\hline
\end{tabular}

139392 with low vision in the governorate. The prevalence of blindness of $12 \%$ (age $50+$ ) is lower than found in the earlier studies in the Nile Delta and is similar to findings (unpublished) from recent work in Menia governorate of Egypt.

Egypt is not a poor country; median per capita income is $\$ 1390$ per year; however $21.7 \%$ of the population live below the poverty line (earning \$327 per year). Almost all of the adult population in Menofiya has access to the general electrical network and $78 \%$ have access to piped water in the household. Most individuals report that the primary source of income in their household is from trading, suggesting that there are disposable sources of income. Radios and TVs are owned by the vast majority of households throughout the governorate, which also suggests disposable income. The number of healthcare providers and eye care providers in the governorate is both adequate in number and accessible in terms of distance and cost of service; $75 \%$ of the adults surveyed lived within $9 \mathrm{~km}$ of an eye care provider. Nevertheless, avoidable or curable blindness in Menofiya was common.

As expected, age was the primary predictor of blindness in the adult population. Almost half of all of the blind people $(47.9 \%)$ in the study population were age 70 years and over. Being female and unmarried (in most cases, widowed) was also independently associated with blindness in this population. These findings are consistent with a meta-analysis of blindness surveys, ${ }^{3}$ which showed that women were consistently more likely to be blind (independent of age) compared to men. Socioeconomic status (measured by building type or source of income) was not associated with blindness suggesting that characteristics unrelated to financial considerations predict blindness in this population.

It was noted in a previous anthropological study in a nearby governorate that there are two prevalent "hierarchies of resort" (utilisation patterns) for eye diseases in the adult population. ${ }^{11}$ These distinct two step sequences to using services involve treatment within the family followed either by treatment by a traditional healer or treatment by a biomedical eye care provider. The study noted that most people, particularly women, never proceeded beyond the first step (treatment within the family). Men were twice as likely to visit an eye care provider as women. The low uptake of cataract surgery in this population suggests that decision making remains a significant contribution to patterns of blindness. In the same study population it was noted that visually impaired residents did not admit to problems with vision. ${ }^{12}$ Four possible reasons were suggested: (1) eye disease and vision loss are so common that people only regard visual impairment or blindness as the complete absence of vision, (2) cultural beliefs discourage complaining as it implies questioning the "will of God," (3) mentioning eye disease may cause it to occur (the power of the word), and (4) the elderly may not feel that they require normal vision to conduct activities of daily living.
Individuals not on the general network for sanitation services had a 4.3 -fold (95\% CI 0.6 to 32.8 ) odds of blindness compared to those on the network; this finding may confirm previous findings of the association between sanitation and active trachoma. ${ }^{13}$ Our study, however, does not have adequate power to test the association between cause of blindness and sanitation facilities and the long period between exposure and blindness due to trachoma limits interpretation.

Interpretation of our findings is limited by a number of factors. Many recent blindness surveys in the field have included more thorough and sophisticated clinical examination, particularly to identify glaucoma, than this survey did. The additional cost of such examination is significant and its major usefulness is in improving the accuracy of glaucoma diagnosis at an early stage. We expected that much of the blindness in our population would be the result of cataract and corneal disease, which can be diagnosed with reasonable accuracy by the examination methods we used. It is possible that glaucoma and diabetic retinopathy were underdiagnosed and we would not use our findings to determine the prevalence of these diseases. Socioeconomic status was measured using type of building, primary source of family income, and occupation as proxy indicators. We may not have accurately captured levels of economic wellbeing in this population which would limit our ability to interpret the socioeconomic findings in our study. Finally, our failure to examine $19.2 \%$ of the adult population, particularly men 50 59 years of age, may have led to an overestimation of blindness in the community. It was noted in a previous survey that, in fact, the blind are less likely to present for vision screening than the sighted. ${ }^{7}$ However, if all of those not examined were not blind, our overall blindness prevalence would still be $9.4 \%$.

Our findings were similar to findings from a survey in Lebanon $^{14}$ in which the authors suggested that the large backlog of unoperated cataract was not due to the lack of cataract surgeons or for economic reasons (surgery is free of charge for needy individuals in Lebanon). Instead, community based factors (education and acceptance of surgery) were noted as the likely reasons for the cataract backlog. Our findings suggest that simply increasing the number of eye care providers is unlikely to result in a reduction of blindness; patients are not using the available services to maximum capacity. The quality of outcome of eye care service received is also likely to be a barrier to the uptake of services in the population; in this population over $90 \%$ of the eyes with cataract surgery were aphakic and almost half of them were blind $(<6 / 60)$. Improving of the quality of services will help ensure that services received do not lead to continued vision loss.

It is likely that a significant impact on blindness prevalence in the governorate cannot be achieved without a well orchestrated community based effort. This effort will need to focus on gender sensitive approaches to promote eye care 
services to the most elderly in the population. Anthropological assessment of eye care utilisation is needed to design specific community based efforts targeting women, particularly unmarried (often widowed) women. Reaching this population will require strategies that focus on decision making within families. Our findings, if replicated in other governorates of Egypt, may point the way to successfully implementing Vision 2020 in Egypt.

\section{ACKNOWLEDGEMENTS}

The Menofiya Blindness and Trachoma Survey was supported by Pfizer Inc, the Al Noor Foundation, the Ministry of Health Menofiya, the Edna McConnell Clark Foundation, and the BC Centre for Epidemiologic and International Ophthalmology, to whom we are grateful. The project could not have been carried out with the support of the governor, health officials, and population of Menofiya. In particular, the authors are grateful for the support and assistance from Dr Gamal ezz al Arab, Dr Nagah Tawfik, and Mr Sayed Hanafy (Al Noor Foundation), Dr Reda El Gendy ( $\mathrm{MoH}$ Menofiya), Dr Wagida Anwar ( $\mathrm{MoH}$ Cairo), and Dr Ahmed El Hakim (Pfizer, Egypt).

\section{Authors' affiliations}

D Fouad, Department of Biostatistics and Demography, Institute of Statistical Studies and Research, Cairo University, Cairo, Egypt A Mousa, Al Noor Foundation, Cairo, Egypt

P Courtright, Kilimanjaro Centre for Community Ophthalmology, Tumaini University, Moshi, Tanzania and British Columbia Centre for Epidemiologic and International Ophthalmology, University of British Columbia, Vancouver, Canada

\section{REFERENCES}

1 World Health Organization. Vision 2020-the right to sight. Geneva: WHO www.iapb.org.

2 Frick KD, Foster A. The magnitude and cost of global blindness: an increasing problem that can be alleviated. Am J Ophthalmol 2003;135:471-6.

3 Abou-Gareeb I, Lewallen S, Bassett K, et al. Gender and blindness: a metaanalysis of population-based prevalence surveys. Ophthalmic Epidemiol $2001 ; 8: 39-56$

4 Dandona R, Dandona L. Review of findings from the Andhra Pradesh Eye Disease Study: policy implications for eye care services. Indian J Ophthalmol 2001;49:215-34.

5 Dandona R, Dandona L. Socioeconomic status and blindness. Br J Ophthalmol 2001;85:1484-8.

6 Said ME, Goldstein H, Korra A, et al. Prevalence and causes of blindness in urban and rural areas of Egypt. Public Health Reports 1970;85:587-9.

7 Said ME, Goldstein H, Korra A, et al. Distribution of visual acuity in Egypt. Health Services Reports 1974;89:247-255.

8 Said ME, Goldstein H, Korra A, et al. Visual acuity as related to causes of blindness, age and sex in urban and rural Egyptians. Am J Public Health $1971 ; 61: 2433-48$

9 Courtright P, Sheppard J, Schachter J, et al. Trachoma and blindness in the Nile Delta: current patterns and projections for the future in the rural Egyptian population. Br J Ophthalmol 1989;73:536-40.

10 Ezz al Arab G, Tawfik N, el Gendy R, et al. The burden of trachoma in rural Egypt: a population based survey of Menofiya governorate. Br J Ophthalmol 2001;85:1406-10.

11 Lane SD, Millar MI. The "Hierarchy of Resort" reexamined: status and class differentials as determinants of therapy for eye disease in the Egyptian delta. Urban Anthropol 1987; 16:151-82.

12 Lane SD, Mikhail BI, Reizian A, et al. Socio-cultural aspects of blindness in an Egyptian delta hamlet: visual impairment vs visual disability. Med Anthropol 1993;15:245-60.

13 Courtright $\mathbf{P}$, Sheppard J, Lane S, et al. Latrine ownership as a protective factor in inflammatory trachoma in Egypt. Br J Ophthalmol 1991;75:322-5.

14 Mansour AM, Kassak K, Chaya M, et al. National survey of blindness and low vision in Lebanon. Br J Ophthalmol 1997;81:905-6. 